\title{
Highly Stable, Near-Unity Efficiency Atomically Flat Semiconductor Nanocrystals of CdSe/ZnS Hetero-Nanoplatelets Enabled by ZnS-Shell Hot-Injection Growth
}

\author{
Yemliha Altintas, Ulviyya Quliyeva, Kivanc Gungor, Onur Erdem, Yusuf Kelestemur, \\ Evren Mutlugun, Maksym V. Kovalenko, and Hilmi Volkan Demir**
}

Colloidal semiconductor nanoplatelets (NPLs) offer important benefits in nanocrystal optoelectronics with their unique excitonic properties. For NPLs, colloidal atomic layer deposition (c-ALD) provides the ability to produce their core/shell heterostructures. However, as c-ALD takes place at room temperature, this technique allows for only limited stability and low quantum yield. Here, highly stable, near-unity efficiency $\mathrm{CdSe/ZnS} \mathrm{NPLs} \mathrm{are} \mathrm{shown} \mathrm{using}$ hot-injection (HI) shell growth performed at $573 \mathrm{~K}$, enabling routinely reproducible quantum yields up to $98 \%$. These $\mathrm{CdSe} / \mathrm{ZnS} \mathrm{HI}$-shell hetero-NPLs fully recover their initial photoluminescence $(\mathrm{PL})$ intensity in solution after a heating cycle from 300 to $525 \mathrm{~K}$ under inert gas atmosphere, and their solid films exhibit $100 \%$ recovery of their initial PL intensity after a heating cycle up to $400 \mathrm{~K}$ under ambient atmosphere, by far outperforming the control group of c-ALD shell-coated CdSe/ZnS NPLs, which can sustain only $20 \%$ of their PL. In optical gain measurements, these core/HI-shell NPLs exhibit ultralow gain thresholds reaching $\approx 7 \mu \mathrm{J} \mathrm{cm}^{-2}$. Despite being annealed at $500 \mathrm{~K}$, these ZnS-HI-shell NPLs possess low gain thresholds as small as $25 \mu \mathrm{cm}^{-2}$. These findings indicate that the proposed $573 \mathrm{~K} \mathrm{HI}$-shell-grown CdSe/ZnS NPLs hold great promise for extraordinarily high performance in nanocrystal optoelectronics.

\section{Introduction}

Nowadays, chemically synthesized semiconductor nanocrystals (NCs) have become an important and exciting class of nanomaterials. These free-standing NCs are obtained with the colloidal synthesis, enabling unique opportunities to precisely control their size, shape, structure, and composition. ${ }^{[1]}$ To this end, in the development of NC syntheses, a major breakthrough came in the middle of $1990 \mathrm{~s}$ when the hot-injection (HI) crystal growth technique was demonstrated colloidally to produce monodisperse Cd-based NCs. ${ }^{[2]}$ Thus far, such NCs of spherical quantum dots (QDs) have been extensively studied and exploited. ${ }^{[3-7]}$ Previously, different than being spherical in shape, a new family of NCs that are atomically flat and of only few monolayers in thickness was obtained with excellent control over their quasi-2D structure. ${ }^{[8]}$ This type of flat NCs as commonly known as semiconductor
Dr. Y. Altintas, U. Quliyeva, Dr. K. Gungor, O. Erdem,

Dr. Y. Kelestemur, Prof. E. Mutlugun, Prof. H. V. Demir

Department of Electrical and Electronics Engineering

and Department of Physics

UNAM - Institute of Materials Science and Nanotechnology

Bilkent University

Ankara 06800, Turkey

E-mail: hvdemir@ntu.edu.sg,volkan@bilkent.edu.tr

Dr. Y. Altintas, Prof. E. Mutlugun

Department of Materials Science and Nanotechnology

and Department of Electrical-Electronics Engineering

Abdullah Gül University

Kayseri TR-38080, Turkey

Dr. Y. Kelestemur, Prof. M. V. Kovalenko

Department of Chemistry and Applied Biosciences

ETH Zürich

Zürich $\mathrm{CH}-8093$, Switzerland

The ORCID identification number(s) for the author(s) of this article

can be found under https://doi.org/10.1002/smll.201804854.
Dr. Y. Kelestemur, Prof. M. V. Kovalenko

Empa-Swiss Federal Laboratories for Material Science and Technology

Dübendorf $\mathrm{CH}-8600$, Switzerland

Prof. H. V. Demir

Luminous! Center of Excellence for Semiconductor Lighting and Displays School of Electrical and Electronic Engineering

School of Physical and Mathematical Sciences

School of Materials Science and Nanotechnology

Nanyang Technological University

Singapore 639798, Singapore

DOI: 10.1002/smll.201804854 
nanoplatelets (NPLs), or alternatively as colloidal quantum wells (QWs), offer new possibilities based on their 1D tight quantum confinement characteristics in colloidal optoelectronics. ${ }^{[9]}$ For example, these NPLs having magic-sized vertical thickness exhibit ultranarrow emission with no (or reduced) inhomogeneous broadening, accompanied with giant oscillator strengths, large absorption cross-sections and molar extinction coefficients when compared to QDs. ${ }^{[9-11]}$ All these properties make NPLs highly promising candidates for high-performance colloidal lasing as well as possibly other colloidal optoelectronic applications. ${ }^{[12-14]}$ Nevertheless, there are important and challenging problems that need to be resolved related with their stability to ensure extended shelf-lifetime, efficient light emission, and lasing, which involves high operating temperatures and high photon energy excitations. ${ }^{[15]}$

An effective method for tackling the stability issue is the growth of a semiconductor layer around the core NPLs. This approach generally helps to reduce the surface nonradiative recombination sites by passivating surface traps, leading to increased quantum yield and decreased emission blinking at a single particle level. ${ }^{[16-20]}$ Among the shell structures used for CdSe-core NPLs, the most notable ones demonstrated thus far include $\mathrm{CdS}^{[16,21-23]}$ and $\mathrm{ZnS},{ }^{[20,23]}$ which results in quasi-type-II and -type-I band alignment structures, respectively. In the past few years, research on the core/shell NPLs has concentrated mostly on the colloidal synthesis of CdSe/CdS core/shell NPLs owing to the smaller lattice mismatch between these materials and the resulting quasi-type II nature of electronic structure enabling highly tunable excitonic features. ${ }^{[19,21-23]}$ For example, Rossinelli et al. have recently reported the uniform growth $\mathrm{CdS}$ shell on CdSe NPLs at higher temperatures resulting in narrower emission linewidth $(\approx 20 \mathrm{~nm})$ with suppressed blinking and moderately high photoluminescence quantum yield (QY) of $55-60 \% .{ }^{[22]}$ However, the little band-offset for electrons in CdS shell necessitates a new shell structure with a large bandoffset, thus providing enhanced environmental stability and high stability under high-temperature working conditions. ${ }^{[24]}$

Such a large band-offset can be achieved with the growth of $\mathrm{ZnS}$ shell, which can substantially reduce trap sites. The previous studies on the $\mathrm{ZnS}$ shell growth commonly relied on the so-called colloidal atomic layer deposition (c-ALD) and these $\mathrm{CdSe} / \mathrm{ZnS}$ core/shell NPLs possess very low QY levels in the range of $1-4 \% .{ }^{[20,23]}$ In addition to the lower QY, conventional c-ALD approach is time-consuming and a large amount of precursor is wasted during its tedious synthesis protocol. Also, an undesirable homogenous nucleation of shell material is easily induced if the cleaning process is not performed several times after each semi-layer. Moreover, the resulting core/shell NPLs suffer from the poor colloidal stability after multiple cleaning steps. In this context, hot-injection shell growth approach potentially offers solutions to synthesize highly uniform and crystalline $\mathrm{CdSe} / \mathrm{ZnS}$ core/shell NPLs together with narrow emission bandwidth, improved QY and enhanced thermal stability if performed at high enough temperatures. The most recent work on these NPLs has been reported by Polovitsyn et al., employing the $\mathrm{ZnS}$ shell growth at moderate temperatures of $373-423 \mathrm{~K}$. The reported QY of that previous work is 50-60\%, which has thus far been the highest value attained in the literature for $\mathrm{CdSe} / \mathrm{ZnS}$ core/shell NPLs. ${ }^{[20]}$ However, there had been no report on the growth on the $\mathrm{ZnS}$ shell beyond $500 \mathrm{~K}$ to date, which would enable much further improved efficiency and enhanced stability at the same time, which is desired for high-performance colloidal optoelectronic applications.

Here we present the synthesis of CdSe/ZnS core/shell NPLs with QY close to unity (98\%), enabled by the ZnS shell hot-injection growth at a high temperature of $573 \mathrm{~K}$, reaching unprecedented levels of stability and achieving superior optical gain performance. These CdSe/ZnS core/HI-shell NPLs are synthesized without any side-product and with the benefit of a facile purification and isolation procedure, as compared to those of the c-ALD technique. In this work, the resulting absolute photoluminescence (PL) QY of the core/HI-shell NPLs ranges from $85 \%$ to $98 \%$ depending on the shell precursors as well as the reaction conditions, which is attained reproducibly.

In addition, we observe that the thermal stability is greatly enhanced by using the HI-shell growth approach beyond $500 \mathrm{~K}$. By systematically conducting thermal tests under ambient air conditions which induce additional degradation, we observe that the thick-shell CdSe/ZnS core/shell NPLs completely recover their initial PL intensity (100\% PL recovery) during a heating cycle from 300 to $400 \mathrm{~K}$ while exhibiting 76\% PL recovery for the range of 300-525 K. This HI thick-shell sample also exhibits the best performance in UV stability tests and preserves their higher QY even after multiple cleaning steps. Previously, the thermal stability of different NPLs was reported by Rowland et al. for CdSe/CdS core/shell NPLs under vacuum. ${ }^{[19]}$ In this previous study, as a benchmark, the heating cycle up to $450 \mathrm{~K}$ yields fully reversible PL intensity under vacuum for $\mathrm{CdSe} / \mathrm{CdS}$ core/shell NPLs with six monolayers of CdS shell that was produced using the c-ALD method; however, the PL intensity was found to drop to $60 \%$ at the end of heating cycle up to $500 \mathrm{~K}$. These results show that the CdSe/ZnS hetero-nanoplatelets synthesized herein exhibit superior thermal stability compared to their predecessors.

Finally, we have studied the optical gain performances of $\mathrm{HI}$ $\mathrm{CdSe} / \mathrm{ZnS}$ core/shell hetero-nanoplatelets. With their enhanced optical properties and superior thermal stability, we achieve low gain threshold values as low as $\approx 7 \mu \mathrm{J} \mathrm{cm}^{-2}$ under femtosecondpulsed excitation. Superior thermal stability is also observed in optical measurements for HI NPLs. Films of HI NPLs annealed at 400-500 K showed significantly lower ASE threshold values. Being a major limitation for practical lasing applications, the substantially improved thermal stability of $\mathrm{HI} \mathrm{CdSe} / \mathrm{ZnS}$ core/ shell NPLs will be an important step for the realization of lasers with colloidal nanocrystals as active gain medium.

\section{Results and Discussion}

We utilized and modified the hot-injection shell growth recipe reported by Rossinelli et al. for quasi-type-II CdSe/CdS core/ shell NPLs. ${ }^{[22]}$ In our study, Zn-acetate and octanethiol were used as Zn and S precursors for ZnS shell coating, respectively. The shell growth was carried out at $573 \mathrm{~K}$ due to the effective utilization of octanethiol, which has relatively low reactivity at low temperature. During the synthesis, aliquots were taken at regular intervals to characterize the resulting optical properties. The PL and absorbance spectra of CdSe/ZnS core/shell NPLs 


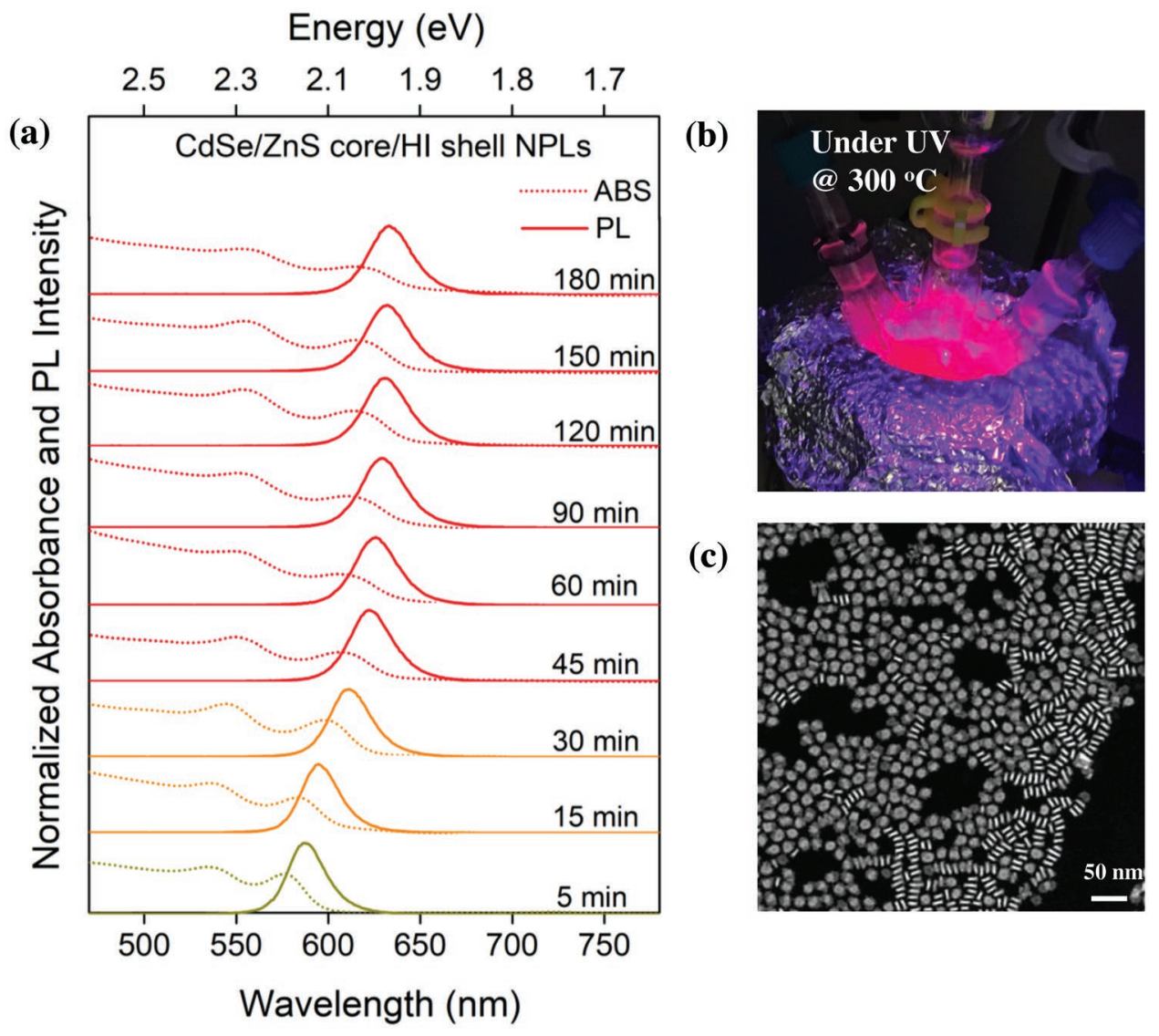

Figure 1. a) Normalized absorbance and photoluminescence spectra of CdSe/ZnS core/hot-injection shell nanoplatelet (core/HI-shell NPL) samples parameterized with respect to the shell growth time. b) Photographs of a core/HI-shell NPL sample at $573 \mathrm{~K}\left(300{ }^{\circ} \mathrm{C}\right)$ with UV illumination during the synthesis. This unique continuous emission of the synthesized NPL well at $573 \mathrm{~K}\left(300^{\circ} \mathrm{C}\right)$ indicates its high thermal stability unlike standard NPL growth where the emission fully quenches at high temperature. c) TEM image of the synthesized core/HI-shell NPL (scale bar: $50 \mathrm{~nm}$ ).

using different shell growth time are presented in Figure 1a. With the formation of $\mathrm{ZnS}$ shell, strongly redshifted excitonic features are observed. The red shift in PL emission is recorded as $75 \mathrm{~nm}$ at $5 \mathrm{~min}, 98 \mathrm{~nm}$ at $30 \mathrm{~min}, 112 \mathrm{~nm}$ at $60 \mathrm{~min}, 116 \mathrm{~nm}$ at $120 \mathrm{~min}$, and $120 \mathrm{~nm}$ at $180 \mathrm{~min}$ with respect to the peak emission wavelength of core NPLs $(\approx 513 \mathrm{~nm})$. In addition to the delocalization of electron and hole wavefunctions to the whole core/shell structure, the change in the effective dielectric constant contributed to the observed strongly redshifted PL behavior, which is not common for semiconductor NCs having type-I electronic structure. ${ }^{[20]}$ The full-width-half-maximum (FWHM) of the PL emission during the shell growth first increased to $22 \mathrm{~nm}$ during the first $30 \mathrm{~min}$ growth time, then increased to $26 \mathrm{~nm}$ at $90 \mathrm{~min}$, and finally reached $29 \mathrm{~nm}$ at $180 \mathrm{~min}$. This broadening in the emission linewidth is attributed to the enhanced exciton-phonon coupling within these core/shell heterostructures, increased strain with the formation $\mathrm{ZnS}$ shell having large lattice mismatch between the CdSe core and possibly slight thickness variation within the NPLs. ${ }^{[2,25]} \mathrm{We}$ have also measured the QY of the core/shell NPLs depending on the shell growth time. In the first $30 \mathrm{~min}$ of the growth time, QY of sample increased dramatically from $4 \%$ (2.5 min) to $60 \%$ (30 $\mathrm{min})$, suggesting the effective passivation of surface trap sites with the ZnS shell. Then, QY of the sample reached a maximum value of $70 \%$ at $60 \mathrm{~min}$, and from 60 to $180 \mathrm{~min}$ of the shell growth time, QY of the sample decreased from $70 \%$ to $50 \%$, which is expected due to increased strain and/or defect sites with the formation of thicker $\mathrm{ZnS}$ shell. Figure $1 \mathrm{~b}$ shows the photographs of $\mathrm{CdSe} / \mathrm{ZnS}$ core/HI-shell NPL monitored at $573 \mathrm{~K}$, with PL emission under UV illumination, indicating the thermal stability of as-synthesized HI-shell NPLs. Transmission electron microscopy (TEM) image of the hot-injection sample is given in Figure 1c. The thickness of the synthesized NPLs is $\approx 4.35 \pm 0.56 \mathrm{~nm}$, measured from TEM images.

To further improve the quality of the synthesized CdSe/ZnS core/HI-shell NPLs, we studied the synthesis conditions by systematically tuning the shell growth time, precursors and ligand concentrations. For the synthesis, we employed oleic acid (OA) and oleylamine (OLA) as the ligand. OA was added at the beginning of the synthesis together with $\mathrm{Zn}$ precursor, octadecene (ODE) and CdSe core NPL. First, we investigated the effect of OA on the resulting optical and structural properties of core/ shell NPLs by using three different amounts of OA $(100,500$, and $1000 \mu \mathrm{L})$ with the constant volume $(500 \mu \mathrm{L})$ of the OLA. The absorbance, PL, time-resolved fluorescence (TRF) decay curves, and TEM images of the samples are given in Figures S1 and S2 
(Supporting Information). The excitonic features of the resulting core/shell NPLs are further redshifted with the increased amount of OA, suggesting the preferential growth in the vertical direction and resulting in further redshifted excitonic features. This is also verified with the measured thicknesses from TEM images and the thickness of the NPLs increased with increasing the amount of OA from $2.66 \pm 0.26 \mathrm{~nm}$ (for the case of $100 \mu \mathrm{L} \mathrm{OA}$ ) to $4.07 \pm 0.38 \mathrm{~nm}$ (for the case of $1000 \mu \mathrm{L}$ OA). The PL emission peak changed from 592 to $602 \mathrm{~nm}$ and finally to $625 \mathrm{~nm}$ with respect to the used amount of OA, while the QYs of the samples are $75 \%, 85 \%$, and $56 \%$, respectively, as presented in Table S1 (Supporting Information). From the analyses of the high-resolution transmission electron microscopy (HR-TEM) and high-angle annular dark-field scanning transmission electron microscopy (HAADF-STEM) images of these samples, uniform and homogeneous shell growth was found to be achieved using $500 \mu \mathrm{L}$ of OA. From the TRF measurements, the amplitude-averaged fluorescence lifetimes $\left(\tau_{\mathrm{av}}\right)$ of core/shell NPLs are calculated by fitting with multiexponential decay functions due to their complex decay kinetics. We observed continuously decreased lifetimes from $\approx 13.9$ to $6.0 \mathrm{~ns}$ with increasing the amount of OA (Table S2, Supporting Information). The fluorescence decay curves are mainly composed of two exponential decays with lifetimes of 46-40 and 13-12 ns. For the case of the core/shell NPLs synthesized with $1000 \mu \mathrm{L}$ of OA, we observed an additional lifetime component of $0.5 \mathrm{~ns}$. This component might be attributed to nonradiative decay processes and explained the observed lower QY of the sample. ${ }^{[26]}$

Etching of the CdSe core NPLs at higher temperatures within the presence of OLA has been previously reported with the reduced lateral dimensions. ${ }^{[22]}$ Therefore, during our synthesis, we introduced OLA at a later stage to reduce the effect of etching. Also, we observe the formation of rough surfaces from the TEM images having thicker shell at the edges and thinner shell at the central parts (Figures S2 and S4, Supporting Information). This might imply a distinct growth mechanism for the shell layers, starting mainly from the sides and covering the larger surfaces. Three different amounts of OLA were used in the synthesis as none, $500 \mu \mathrm{L}$, and $1000 \mu \mathrm{L}$ of OLA together with $500 \mu \mathrm{L}$ of a constant amount of OA. The absorbance, PL, and TRF decay curves are given in Figure S3 (Supporting Information). In the absence of OLA, QY of the sample decreased to $69 \%$ and FWHM of the sample increases to $31 \mathrm{~nm}$. The heavy- and light-hole transitions in absorbance spectra do not resolve clearly when OLA is absent in the reaction, suggesting the nonuniform growth of $\mathrm{ZnS}$ layers. With the addition of OLA, the resulting core/shell NPLs exhibit enhanced QY with well-resolved excitonic features (Table S3, Supporting Information). While QY of the sample synthesized using $500 \mu \mathrm{L}$ of OLA $(\approx 85 \%)$ is slightly higher than that synthesized with $1000 \mu \mathrm{L}$ of OLA $(\approx 82 \%)$, FWHM of both the samples are the same as $24 \mathrm{~nm}$. The uniform shell formation in the NPL synthesis is obtained by using $500 \mu \mathrm{L}$ of OLA as shown in Figure S4 (Supporting Information). PL decays of all three samples are nearly identical with $\approx 95 \%$ of the contribution coming from two exponential components having lifetimes of $\approx 40-38$ and $\approx 12$ ns (Table S4, Supporting Information). However, due to the nonradiative decay processes such as charge trapping, the fast lifetime component of the sample synthesized without using
OLA is stronger than the others. These experimental findings have shown the importance of the addition of OLA for the synthesis of highly efficient NPLs, which can be explained with the Covalent Bond Classification (CBC) method developed by Green. ${ }^{[27,28]}$ According the CBC method describing the interaction of the ligands with the surface of NCs, while cation rich surfaces can be effectively passivated by using X-type ligands such as carboxylates providing charge neutrality, ${ }^{[29]}$ the cations on the neutral surfaces acting as a Lewis acid can be passivated with L-type ligands such as amines known as a Lewis base. Thus, the synthesis of core/shell NPLs using both OLA and OA would result in the proper passivation of surfaces, enabling higher QY as compared to the core/shell NPLs synthesized without OLA. The proper passivation of the surfaces is also further verified from the TRF measurements with the decreased contribution of the fastest lifetime component.

The best result in the CdSe/ZnS core/HI-shell synthesis was obtained by using the combination of $500 \mu \mathrm{L}$ of OLA and $500 \mu \mathrm{L}$ of $\mathrm{OA}$ in accordance with their shape, QY and uniformity of the synthesized NPLs. This recipe is referred to as HI thin-shell recipe. The absorbance and PL spectra of the synthesized CdSe/ZnS core/HI thin-shell sample are given in Figure 2a. The FWHM, peak emission wavelength, and QY of this sample are $23 \mathrm{~nm}, 602 \mathrm{~nm}$, and 85\%, respectively. From TEM images in Figure 2c, the vertical thickness of the CdSe/ $\mathrm{ZnS}$ core/HI thin-shell sample is measured as $3.04 \pm 0.3 \mathrm{~nm}$. Using thick-shell (or additional shell coating) is well known to improve the stability, as reported in many earlier works, due to the effective protection from the surrounding environment. ${ }^{[17-22]}$ Here CdSe/ZnS core/HI thick-shell sample was synthesized with some modifications and using extra shell precursor in the HI thin-shell recipe presented in the Experimental Section. The absorbance, PL and high-resolution TEM image of the as-synthesized $\mathrm{CdSe} / \mathrm{ZnS}$ core/HI thick-shell sample are presented in Figure 2b,d. The QY, FWHM, and peak emission wavelength of the sample are $98 \%, 27 \mathrm{~nm}$, and $616 \mathrm{~nm}$, respectively. The core/shell structure is clearly seen from the crosssectional TEM image of the HI thick-shell sample in Figure 2e thanks to the contrast difference between the CdSe core and the ZnS shell. The thickness of the HI thick shell NPLs increased to $4.03 \pm 0.43 \mathrm{~nm}$. A narrow emission bandwidth as low as $21 \mathrm{~nm}$ can be obtained using the thin-shell structure, while a near-unity QY is reproducible using the HI thick-shell. The reproducibility of the synthesis results including the QY and FWHM values in the synthesis of HI thin- and thick-shell NPLs is shown in Table S5 (Supporting Information), which contains 10 different successive experiments to demonstrate the reproducible syntheses. Furthermore, the uniform coating of ZnS shell layers on CdSe core NPL were verified with EDS mapping for HI thick-shell sample in Figure $2 \mathrm{f}-\mathrm{k}$. For further structural characterizations of the HI thin- and thick-shell NPLs, we synthesized both thin and thick samples by using the same 4 ML CdSe core NPLs. Detailed lateral and cross-sectional TEM images of HI thin- and thick-shells grown on the same 4 ML core NPLs are presented in Figure S5 (Supporting Information), along with EDS analyses in Table S6 (Supporting Information). From the quantitative EDS analysis, we further confirmed the growth of thicker $\mathrm{ZnS}$ shell. With the additional ZnS shell coating in the HI thick-shell NPLs, the overall atomic 

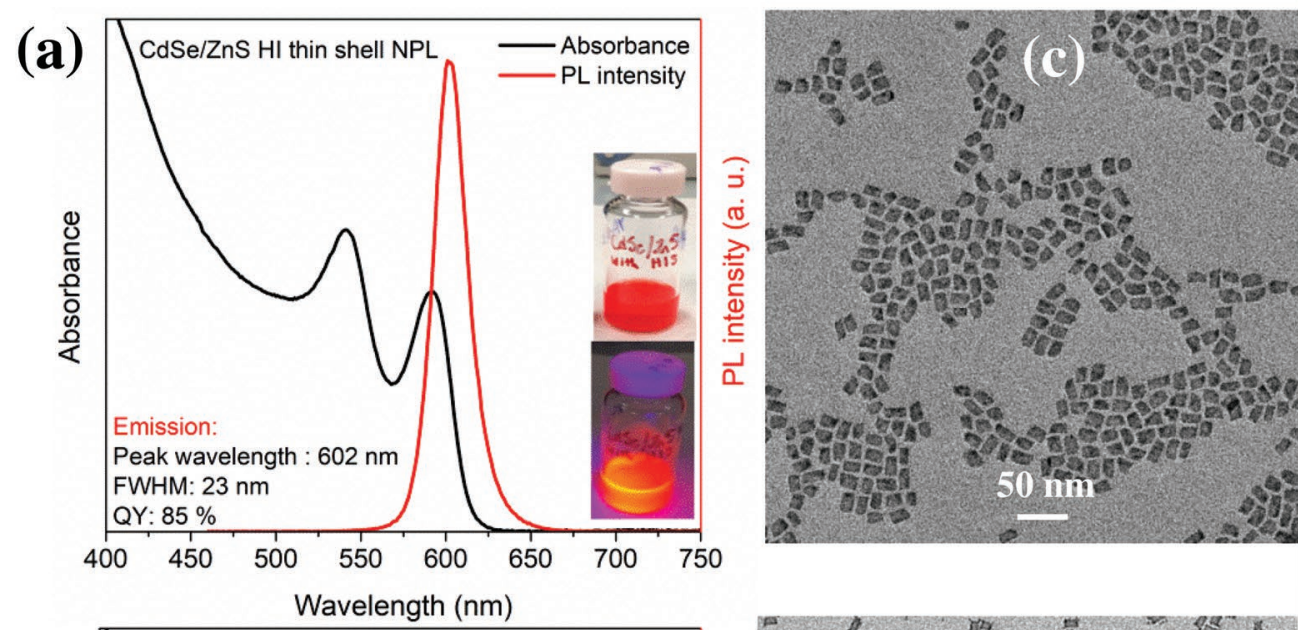

(e)
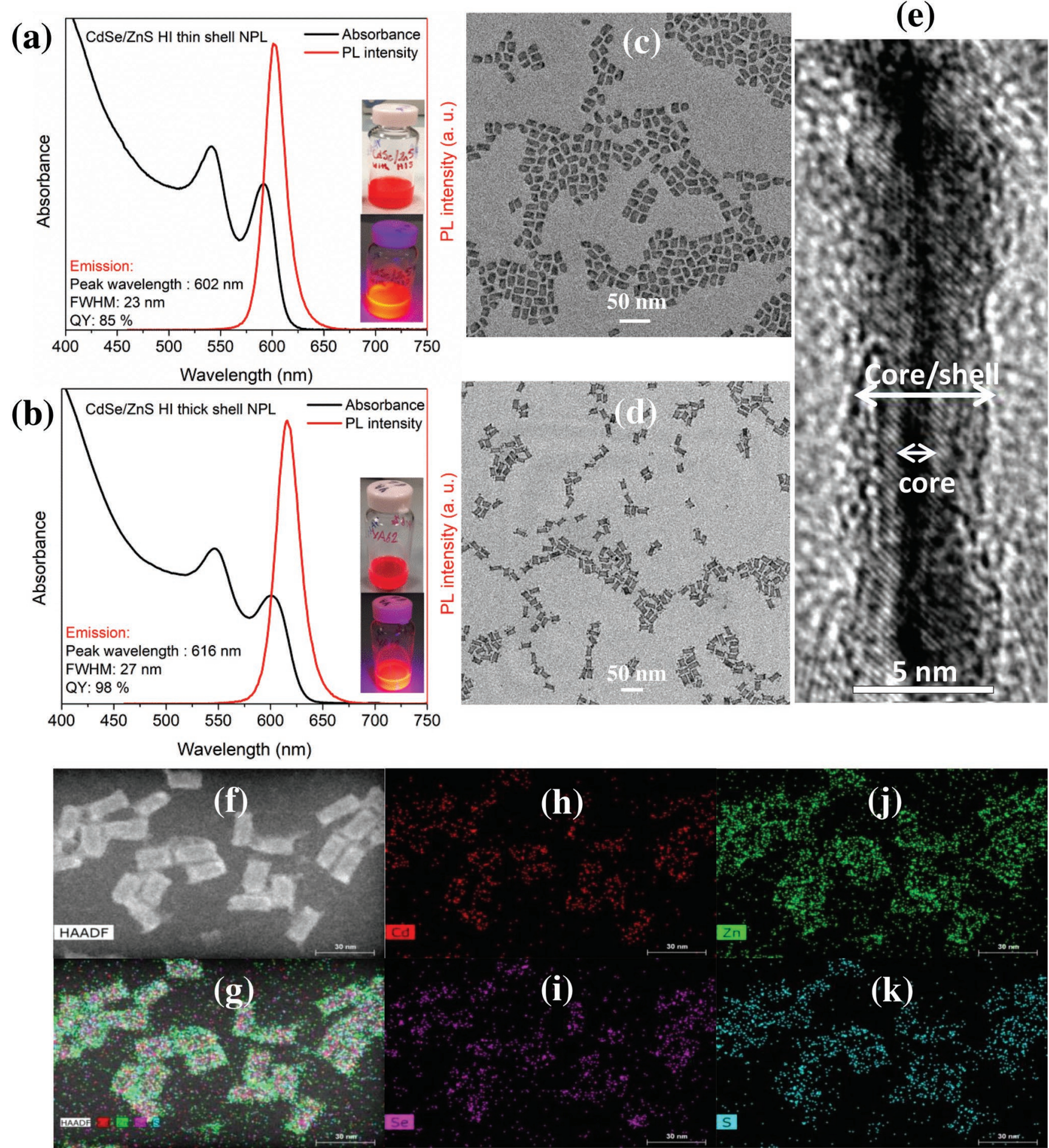

(i)

(k)

Figure 2. Absorbance and PL spectra of the synthesized CdSe/ZnS core/hot-injection (HI) a) thin-shell and b) thick-shell NPL samples, accompanied with their respective sample photographs presented in (a) and (b) under daylight and UV light. HI thin-shell growth reproducibly allows for narrow emission while $\mathrm{HI}$ thick-shell growth consistently enables high QY. TEM images of $\mathrm{CdSe} / \mathrm{ZnS}$ core/HI c) thin-shell and d,e) thick-shell NPL samples. f) HAADF-STEM images of the CdSe/ZnS HI thick-shell NPL sample and g) corresponding EDS mapping with Cd, Se, Zn, and S elements while panels (h)-(k) show single element analysis of CdSe/ZnS HI-shell NPL sample.

percentage of $\mathrm{Zn}$ and $\mathrm{S}$ was found as $47.8 \%$ and $41.1 \%$, respectively, while that in the HI thin-shell sample was measured as $35.6 \%$ for $\mathrm{Zn}$ and $34.0 \%$ for $\mathrm{S}$.
To investigate the in-solution stability of the HI thin- and thick-shell samples, we performed thermal stability, UV-exposure and repetitive purification tests. The thermal stability test 
(a)

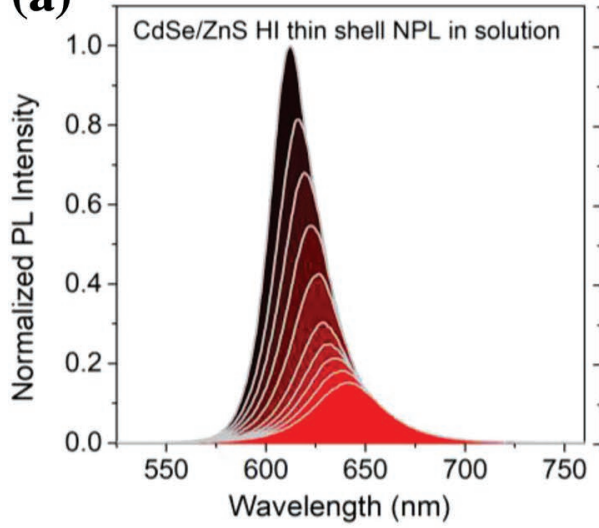

(c)

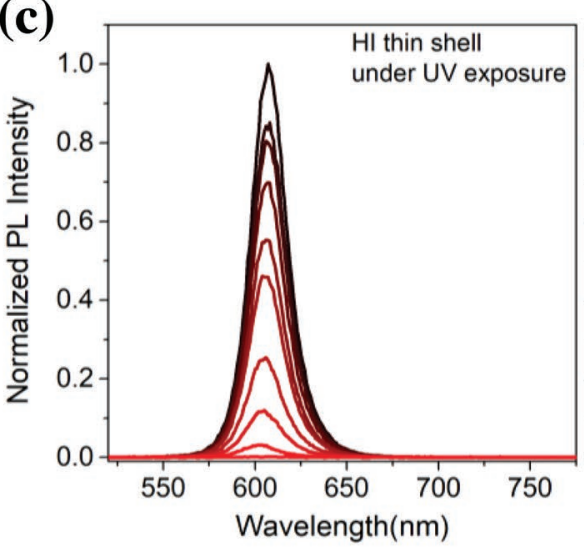

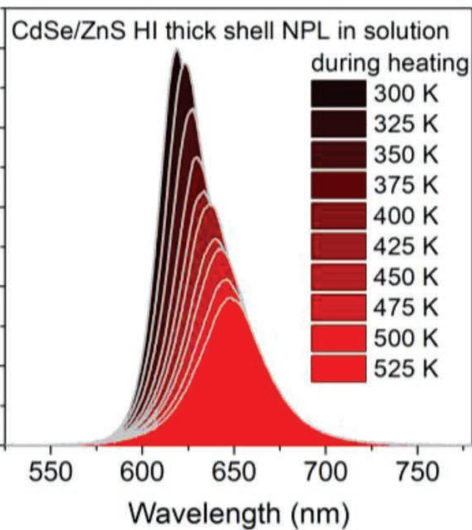

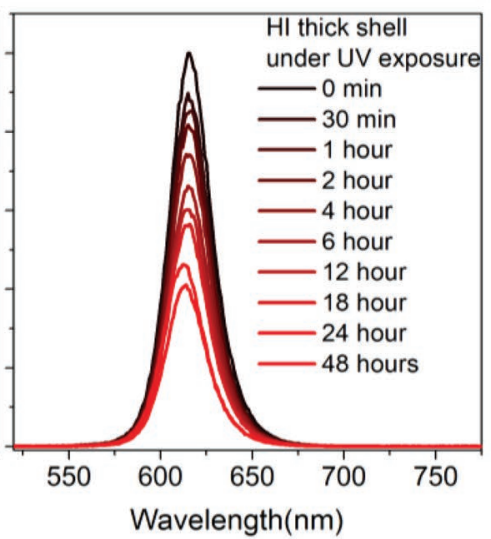

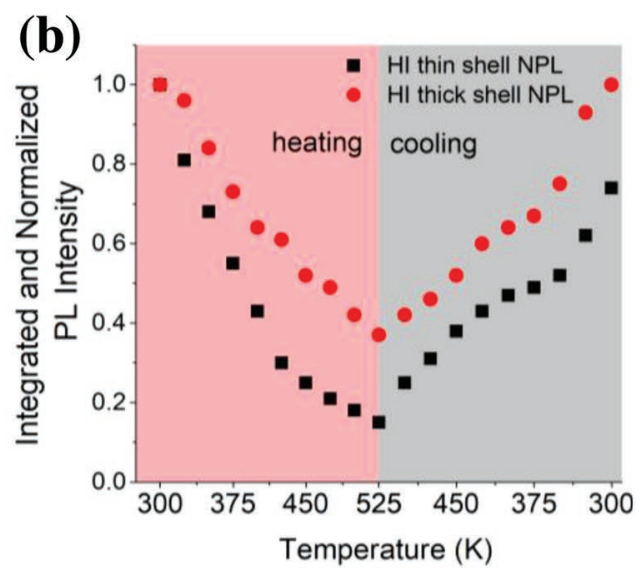

(d)

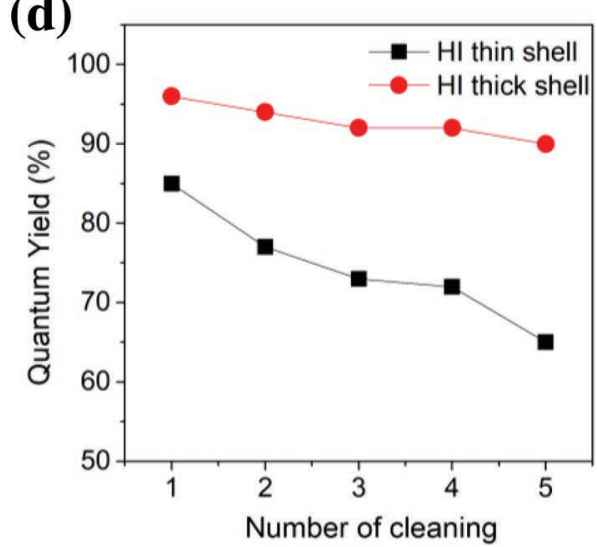

Figure 3. a) Normalized PL intensity of $\mathrm{CdSe} / \mathrm{ZnS} \mathrm{HI}$ thin- and thick-shell NPL in solution (cleaned and precipitated with ethanol, then dissolved in $10 \mathrm{~mL}$ of octadecene) during heating from 300 to $525 \mathrm{~K}$ under argon flow with respect to emission wavelength. b) Integrated PL intensity of CdSe/ZnS $\mathrm{HI}$ thin- and thick-shell NPL samples during temperature elevation. HI thin-shell NPL sample in solution restored $100 \%$ of its initial integrated and normalized PL intensity, while HI thin-shell NPL sample recovered 70\%. c) UV-stability test of CdSe/ZnS HI thin- and thick-shell NPL samples which are synthesized with HI-shell method, d) purification test of the CdSe/ZnS HI thin- and thick-shells.

was conducted monitoring the PL intensity of the sample, which was cleaned and dispersed in $10 \mathrm{~mL}$ of ODE, as a function of the temperature from 300 to $525 \mathrm{~K}$ with $25 \mathrm{~K}$ increments. The thermal test setup is presented in Figure S6 (Supporting Information). The PL intensity of the HI thin- and thick-shell samples decreases and their FWHM increases with the increasing temperature as shown in Figure 3a. Furthermore, the PL emission spectra of the samples redshift by about $30 \mathrm{~nm}$ in the case of thin-shell sample and by $29 \mathrm{~nm}$ in the case of thick-shell at the elevated temperatures. At $400 \mathrm{~K}$, our $\mathrm{HI}$ thin- and thickshell samples unprecedentedly sustain $42 \%$ and $65 \%$ of their initial PL intensities, respectively, which indicates that these HI-shell NPLs are very promising candidates for laser and LED applications since the operating temperature can be as high as $400 \mathrm{~K}$. With further increasing the temperature to $525 \mathrm{~K}$, the HI thin-shell sample preserves $15 \%$ of its initial PL intensity, whereas the HI thick-shell sample maintains $37 \%$ of its initial PL intensity at the same temperature, making these core/ shell NPLs highly appealing for high-power LEDs. During the thermal cycling up to $525 \mathrm{~K}$, the PL emission of the HI thickshell sample has almost fully recovered its initial emission at $300 \mathrm{~K}$, whereas the thin-shell sample preserved $74 \%$ of its spectrally integrated emission as shown in Figure 3b. Second, the photostability of the HI thin- and thick-shell samples was examined by UV-test, which is shown in Figure 3c, by exposure to continuous UV light for 48 hours with a UV-lamp having a peak emission wavelength of $354 \mathrm{~nm}$. After 48-hour continuous UV-exposure, the HI thick-shell sample maintained $40 \%$ of its emission. Finally, the purification test was carried out for the stability of the synthesized HI thin- and thick-shell samples and the QY of the HI thick-shell sample was measured to be more than $91 \%$ even after 5 times cleaning with ethanol, while the QY of the HI thin-shell dropped to $62 \%$. It is hard to preserve the stability of the NCs in organic phase typically after more than three times cleaning due to the separation of the excess ligand.

Colloidal NCs have been widely investigated for use in solid thin films in numerous colloidal optoelectronic devices such as LEDs, ${ }^{[7,14,30]}$ photodetectors, ${ }^{[31]}$ solar cells, ${ }^{[32]}$ and lasers. ${ }^{[12,13,33]}$ For these applications, thermally stable NCs are highly desirable for long-term use and commercial deployment. Therefore, we systematically studied the thermal stability of our HI thinand thick-shell samples at high temperature in comparison to c-ALD shell grown and no-shell NPL samples. Thermal test study was carried out using five different NPL samples, namely CdSe only-core, CdSe/ZnS core/c-ALD thin-shell, CdSe/ZnS 
core/c-ALD thick-shell, CdSe/ZnS core/HI thin-shell, and $\mathrm{CdSe} / \mathrm{ZnS}$ core/HI thick-shell NPLs. Here $2 \mathrm{ML}$ shell coated NPLs using c-ALD technique is referred to as thin-shell, while 5 ML coated sample is, as the c-ALD thick-shell the PL emission peaks of these c-ALD samples match those of the HI thinand thick-shell samples, respectively (Figure S7 and Table S7, Supporting Information). The structural and optical characterizations of these samples are given in Supporting Information (Figures S8 and S9 and Table S8, Supporting Information).

For the thermal stability test, we have used home-made setup, which is presented in Figure S10 (Supporting Information). The temperature of the film was measured with FLIR type thermal camera, which features $0.1{ }^{\circ} \mathrm{C}$ temperature precision. The PL spectrum was simultaneously taken by using MAYA 2000 model spectrophotometer. All measurements were performed in ambient conditions and the films were prepared without any protective medium and/or sealant. The temperature of the samples was increased from 300 to $525 \mathrm{~K}$, while the PL spectrum of the samples was collected with spectrophotometer every $25 \mathrm{~K}$ temperature change. With the increasing temperature, we observed redshifted and decreased PL intensity from the prepared solid films with increased FWHM as shown in Figures $4 \mathrm{a}, \mathrm{b}$. Initial PL intensity of the only-core, c-ALD thin- and thick-shell samples dramatically decreased during heating from 300 to $400 \mathrm{~K}$. At $400 \mathrm{~K}$, the PL intensity of the only-core, c-ALD thin- and thick-shell samples decreased to $4 \%$, $2 \%$ and $10 \%$ of their initial intensities, respectively, while the HI thin- and thick-shell samples preserved $40 \%$ and $52 \%$ of their initial PL intensities. PL spectra of the only-core, c-ALD thin- and thick-shell samples were not detectable easily at and above $450 \mathrm{~K}$. However, HI thin- and thick-shell samples preserved $20 \%$ and $35 \%$ of their initial intensity values at $450 \mathrm{~K}$ and $6 \%$ and $20 \%$ at $500 \mathrm{~K}$, respectively. Due to the correlation between the integrated PL spectra and QY, we also integrated and normalized PL spectra of the samples in Figure 4b. The deceleration rate in the PL spectra of the HI thin- and thickshell samples linearly change with the increased temperature.

CdSe core-only NPLs exhibit the lowest thermal stability as compared to the CdSe/ZnS core/shell NPLs regardless of the $\mathrm{ZnS}$ shell thickness and growth approach. The similar behavior has been also reported extensively in many studies that the core/shell NCs exhibit better thermal stability than their coreonly counterparts. ${ }^{[34-36]}$ According to the study reported by Diroll et al., another important factor affecting the thermal stability of the core/shell NCs is the growth temperature of the shell. ${ }^{[37]}$ When the growth temperature of the shell was performed at higher temperatures (as high as $573 \mathrm{~K}$ and above), these core/shell NCs exhibit higher thermal stability than similar core/shell NCs that were synthesized with highly reactive precursors at lower temperatures below $473 \mathrm{~K}$. This finding also verifies the significantly improved thermal stability of the CdSe/ZnS core/shell NPLs synthesized with hot-injection shell growth approach.

Also, the reversibility of PL emission was investigated by using thermal cycling at the elevated temperatures of 350, 400, 450 , and $500 \mathrm{~K}$ such that the samples were first heated from $300 \mathrm{~K}$ to a specific elevated temperature and then cooled back to $300 \mathrm{~K}$ for the only-core, core/c-ALD thin-shell, core/c-ALD thick-shell, core/HI thin-shell, and core/HI thick-shell NPLs.
The results of the thermal stability and PL recovery with thermal cycling for NPLs are shown in Figure 4c. The loss in the PL emission of only-core, core/c-ALD thin-shell, and core/cALD thick-shell at $350 \mathrm{~K}$ is more than $70 \%$ and the loss at $400 \mathrm{~K}$ is $90 \%$. At $350 \mathrm{~K}$, the losses in the PL emission of HI thin- and thick-shell samples are only $30 \%$ and $15 \%$, and the losses at $400 \mathrm{~K}$ are $55 \%$ and $35 \%$. However, after thermal cycling, the PL emission of HI thick-shell NPLs at $350 \mathrm{~K}$ and $400 \mathrm{~K}$ fully recovered its initial PL intensity when cooled to $300 \mathrm{~K}$, while at the same temperature HI thin-shell NPL recovered $90 \%$ and $88 \%$ of the initial PL intensity. The recovery of the loss in the integrated PL emission of the only-core, core/c-ALD thin-shell, and core/c-ALD thick-shell samples is $\approx 40 \%$ at $400 \mathrm{~K}$. At 450 and $500 \mathrm{~K}$ cycling, the PL emission reversibilities of HI thick-shell NPLs are $92 \%$ and $77 \%$, respectively. The HI thick-shell sample in cycling experiment exhibited the best performance in terms of PL reversibility, showing the effective passivation of NPLS with the growth highly crystalline $\mathrm{ZnS}$ shell at higher reaction temperatures.

Previous report by Diroll et al. ${ }^{[37]}$ indicates that reversibility and stability of the PL emission correlates with electron and hole trap states, which are formed during the thermal cycling. Furthermore, in that study, reversibility of the loss in PL emission during the thermal cycling was investigated with different size and shape of CdSe core and CdSe/CdS core/shell NCs and it was found that thermal stability of rod-like core-only and core/thin-shell structured samples is the best among all studied samples. In the study of Wang et al., the authors observed significantly improved stability with the additional silica-coated core/shell NCs. When they performed temperature stability test with the pristine core/shell NCs, their core/shell NCs can retain only $61 \%$ of their initial emission at $473 \mathrm{~K}$ and almost quenched emission at $573 \mathrm{~K} .^{[38]}$ Regarding the InP based QDs, in their work the authors studied the thermal stability of InP/ $\mathrm{ZnS}$ up to $800 \mathrm{~K}$ and the results demonstrated that integrated PL of these NCs decreased to almost $10 \%$ of their initial value at around $500 \mathrm{~K} .{ }^{[39]}$ In our study, owing to the effective protection of the core surface with thick ZnS shell, trap states are passivated and hence HI thick-shell NPLs not only exhibit the best performance among the reported NPL samples, but also have a comparable thermal stability even with the previously reported colloidal OD quantum dots, although having relatively higher surface to volume ratio. ${ }^{[34-36,40]}$

All these advantages of core/HI-shell synthesis imply that the resulting $\mathrm{CdSe} / \mathrm{ZnS}$ hetero-nanoplatelets with substantially enhanced QY and improved thermal stability enables the utilization of those NPLs in high power density applications, e.g., lasing. For this purpose, tremendous research efforts were aimed at synthesizing particles with optimized structure and composition to obtain the lowest gain threshold values with high gain coefficients. ${ }^{[41-43]}$ Among various loss mechanisms, being the most effective, Auger recombination prohibits high performance optical gain in QDs. 3D confinement of QDs increases the uncertainty in momentum which boosts Auger recombination strictly obeying universal volume scaling law. ${ }^{[44]}$ Owing to 1D confinement in NPLs, momentum conservation is more pronounced and Auger recombination rate is significantly diminished. ${ }^{[33,42,45]}$ In addition to suppressed Auger recombination, large absorption cross-section and giant oscillator strength of 
(a)

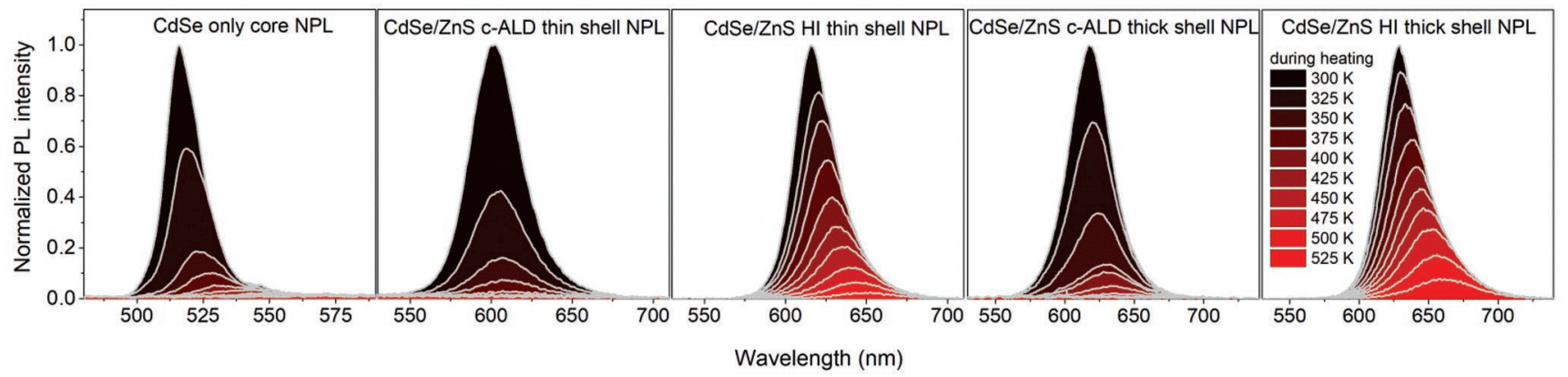

(b)
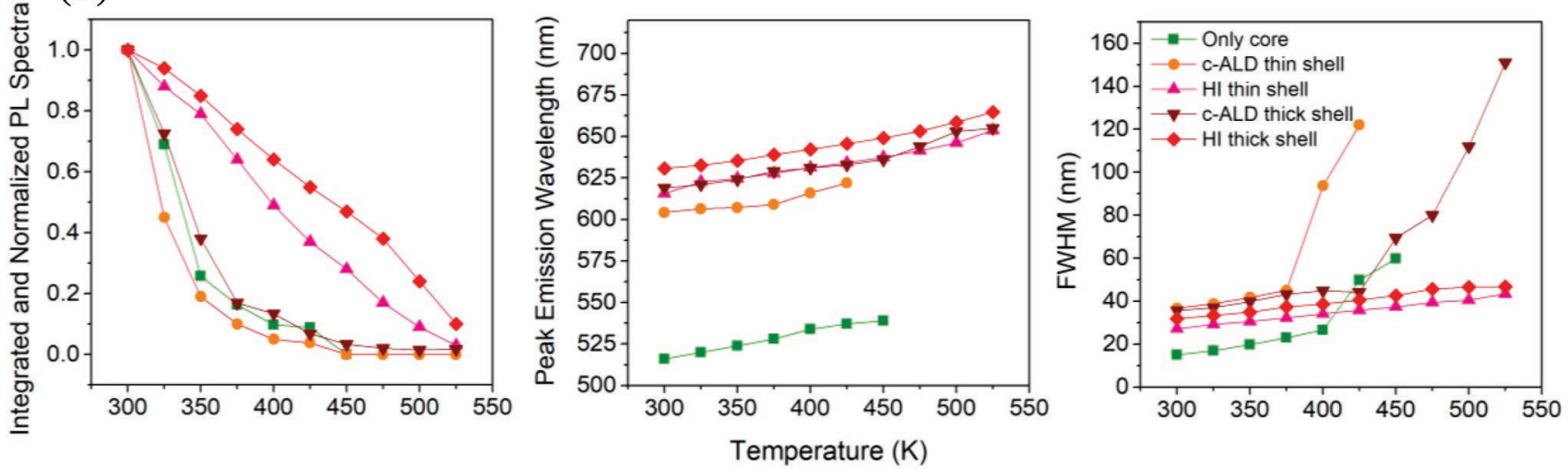

(c)

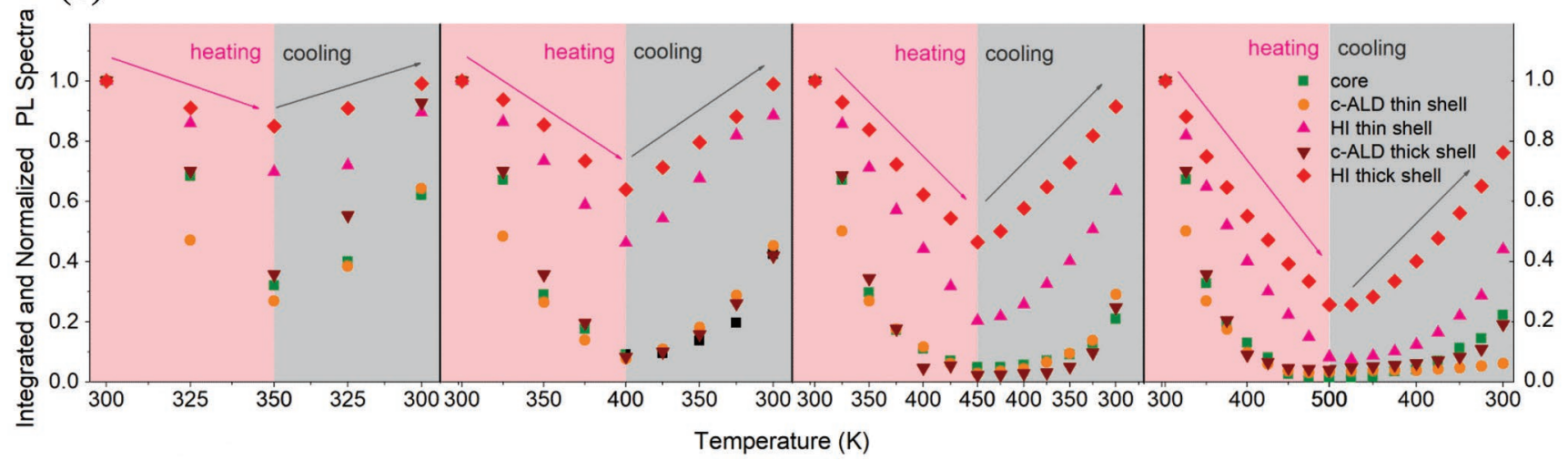

Figure 4. a) Normalized PL intensity and b) Variation of the normalized and integrated PL spectra, peak emission wavelength, and FWHM of the CdSe only-core NPL, CdSe/ZnS c-ALD thin-shell NPL, CdSe/ZnS HI thin-shell NPL, CdSe/ZnS c-ALD thick-shell NPL, and CdSe/ZnS HI thick-shell NPL film samples during heating from 300 to $525 \mathrm{~K}$ under ambient condition. c) Variation of the integrated and normalized PL spectra of all samples during heating and cooling cycles from 300 to $350 \mathrm{~K}$; from 300 to $400 \mathrm{~K}$; from 300 to $450 \mathrm{~K}$; from 300 to $500 \mathrm{~K}$. CdSe/ZnS HI thick-shell NPLs outperformed all other NPLs by realizing unprecedented level of thermal stability and their initial PL intensity is fully recovered up to $450 \mathrm{~K}$ in air condition.

NPLs resulted in exceptional low amplified spontaneous emission (ASE) threshold values reaching $6 \mu \mathrm{J} \mathrm{cm}^{-2} \cdot{ }^{[12]}$ Deposition of $\mathrm{CdS}$ shell layer over CdSe core allows electron wave function to spread over the whole structure further reducing Auger recombination probability. Additionally, CdS shell layer contributes an increase in the absorption cross-section and the photoluminescence quantum yield which are effective in this observed record low ASE threshold. Surrounding the periphery of the NPL with a crown layer also have been shown effective in the reduction of ASE threshold for lasing applications. ${ }^{[13,46,47]}$ Nonetheless, high temperature stability of the NPLs for optical gain applications still remains as a limitation that needs to be addressed.
To address this problem, near-unity QY and high-temperature stability of CdSe/ZnS core/HI-shell NPLs make them perfect candidates for lasing applications. We studied optical gain performance of the HI-shell NPL samples using five different film samples: the only-core NPLs, HI thin-shell NPLs, HI thickshell NPLs, and two sets of annealed HI thin-shell NPLs, one at $400 \mathrm{~K}$ and the other at $500 \mathrm{~K}$. The samples were cleaned three times and concentrated solutions were dispersed in toluene. The films were prepared via spin-casting in glovebox and sealed between two fused silica wafers with epoxy-resin. The annealed samples were sealed after annealing. Highly uniform films of the NPLs were obtained, as shown under ambient lighting and 

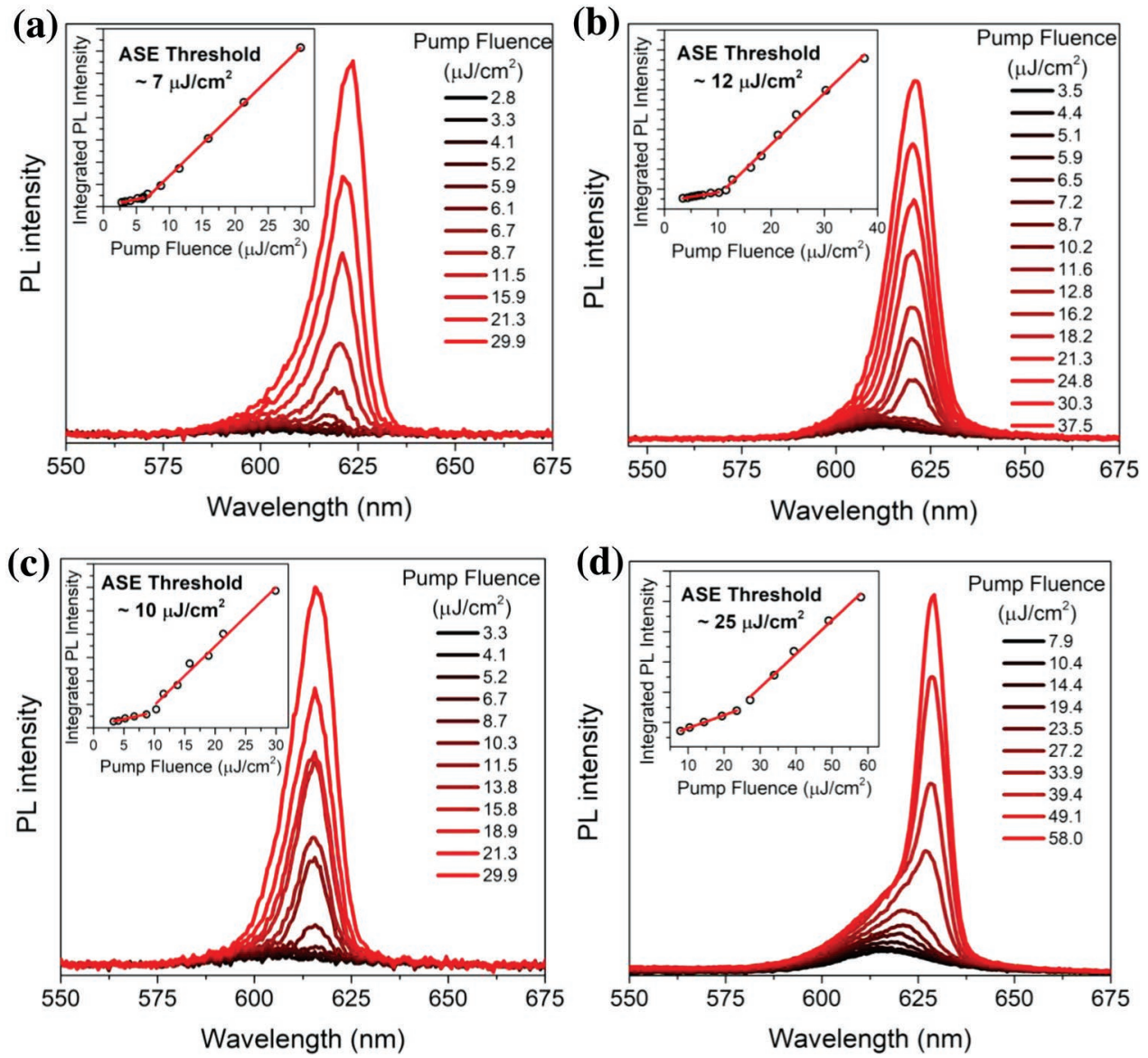

Figure 5. Amplified spontaneous emission spectra of a) $\mathrm{CdSe} / \mathrm{ZnS} \mathrm{HI}$ thin-shell NPL and b) HI thick-shell NPL films. CdSe/ZnS HI thin-shell NPL film c) annealed at $400 \mathrm{~K}$ and d) annealed at $500 \mathrm{~K}$ under stripe excitation pumping. Annealed films at high temperature also display very low gain threshold values (slightly above pristine films) which proves that the annealed film samples possess significant thermal stability. The insets show the integrated emission intensity as a function of the pumping energy density.

UV-excitation in Figure S12 (Supporting Information). $400 \mathrm{~K}$ annealed films under UV-illumination are pictured in Figure S13 (Supporting Information).

Figure 5a,b and their insets present ASE of the spin-coated HI thin-shell and HI thick-shell NPLs under one photon absorption (1PA) excitation. 1PA pumping ASE characterization of the HI NPL films annealed at 400 and $500 \mathrm{~K}$ is also given in Figure 5c,d. Narrow ASE peaks are clearly observed in the PL spectra, which are redshifted compared to their spontaneous emission peak. This redshift is $12 \mathrm{~nm}$ for the core-only NPL film (Figure S14, Supporting Information), $15 \mathrm{~nm}$ for the HI thin-shell NPL film, $8 \mathrm{~nm}$ for HI thick-shell NPL film, $9 \mathrm{~nm}$ for $400 \mathrm{~K}$-annealed NPL film, and $11 \mathrm{~nm}$ for $500 \mathrm{~K}$-annealed NPL film. This redshift observed in ASE peaks is characteristic to Type-I structure of the core/HI-shell NPLs indicating the attractive biexciton interactions. Under 1PA pumping, the HI thin- and HI thick-shell NPLs films have ultralow optical

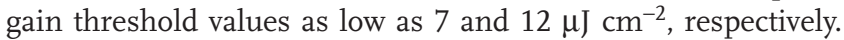
This observed ASE threshold value for the thin-shell HI NPLS is very close to previously reported record low threshold values for II-VI nanocrystals. This reduced ASE threshold values compared to the core NPLs giving $18 \mu \mathrm{J} \mathrm{cm}^{-2}$ can be explained with the enhanced absorption cross-section of HI NPLs and effective passivation of surface trap sites. ZnS shell provides a band offset for the conduction band and prevent interaction of electrons with surface defects. Because of the reduction in trap state interactions, HI-shell NPLs shows near-unity efficiency in spontaneous emission, which also improves their optical gain performance. Owing to the high thermal stability of the HIshell NPLs, their annealed films also exhibit outstanding gain performance and their threshold values are obtained as low

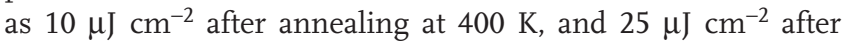
annealing at $500 \mathrm{~K}$.

In conclusion, we have successfully synthesized the highquality CdSe/ZnS core/HI-shell NPLs by using hot-injection shell growth. With this new synthesis approach, CdSe/ZnS core/HI-shell NPLs having near-unity QY have been synthesized in a reproducible way. These new HI CdSe/ZnS core/ shell NPLs exhibit also excellent photo and thermal stability, surpassing the performance of their counterparts synthesized with the conventional c-ALD method. These enhanced optical properties of HI-shell NPLs also enable outstanding optical gain performance with thresholds as low as $7 \mu \mathrm{J} \mathrm{cm}^{-2}$. These findings indicate that these new core/HI-shell NPLs will be an important step for the development of robust continuouswave lasers from the chemically synthesized colloidal NCs and 
various optoelectronic applications requiring high thermal stability.

\section{Experimental Section}

4 ML CdSe Only-Core and CdSe/ZnS Core/c-ALD Shell NPL Synthesis: Detailed synthesis recipes of these NPLs are given in the Supporting Information.

CdSe/ZnS HI Thin-Shell NPL Synthesis: ODE $(5 \mathrm{~mL}), \mathrm{Zn}$ acetate $(0.2 \mathrm{mmol})$, a certain amount of the $4 \mathrm{ML}$ core NPL, and OA $(500 \mu \mathrm{L})$ were introduced to a $50 \mathrm{~mL}$ three-necked flask. The solution was stirred under vacuum at room temperature for an hour to evaporate hexane. Then, the mixture was heated up to $85-90{ }^{\circ} \mathrm{C}$ and kept for $30 \mathrm{~min}$ to completely remove water and/or any other remaining volatile solvents. After degassing step, OLA was added at $90{ }^{\circ} \mathrm{C}$ and the solution was heated to $300{ }^{\circ} \mathrm{C}$ under argon atmosphere. Meanwhile, octanethiol $(70 \mu \mathrm{L})$ in ODE $(4 \mathrm{~mL})$ solution was prepared and it was started to be injected around $170{ }^{\circ} \mathrm{C}$ by using syringe pump. Initially, the rate of the syringe pump was adjusted to $10 \mathrm{~mL} \mathrm{~h}^{-1}$, and then at $250{ }^{\circ} \mathrm{C}$, it was switched to $4 \mathrm{~mL} \mathrm{~h}^{-1}$. After the temperature reached to $300^{\circ} \mathrm{C}$, it was kept at this temperature for an hour to growth of $\mathrm{ZnS}$ shell. After that, the flask was cooled immediately by cold water and hexane $(5 \mathrm{~mL})$ was inserted. No precipitate was attained after the first centrifugation. Later, by ethanol cleaning, the NPLs were precipitated and finally dispersed in hexane.

CdSe/ZnS HI Thick-Shell NPL Synthesis: The recipe was similar to the thin-shell synthesis with slight modifications. Similarly, the CdSe core solution, $\mathrm{Zn}$ acetate, ODE, and $\mathrm{OA}$ were loaded into a $50 \mathrm{~mL}$ of quartz flask and stirred at room temperature under vacuum of 0.1-0.2 mbar for at least $1.5 \mathrm{~h}$. Then, after $50 \mathrm{~min}$ evacuation at 90 ${ }^{\circ} \mathrm{C}$, the system was flushed with argon gas at $85-90{ }^{\circ} \mathrm{C}$ and OLA $(500 \mu \mathrm{L})$ was swiftly injected into the flask. Then, injection pump was adjusted. In the beginning, octanethiol $(70 \mu \mathrm{L})$ in degassed ODE $(2 \mathrm{~mL})$ (prepared in glove box) was injected with the rate of $4 \mathrm{~mL}$ $\mathrm{h}^{-1}$ for $30 \mathrm{~min}$. Then, Zn-oleate solution ${ }^{[48]}$ (given in the Supporting Information) was added drop by drop. We then waited 5 min until it was properly mixed with the reaction mixture. After that, the second $S$ precursor was added by using the syringe pump with the rate of $5 \mathrm{~mL}$ $\mathrm{h}^{-1}$, which was composed of octanethiol $(70 \mu \mathrm{L})$ in degassed ODE $(2 \mathrm{~mL})$. After the growth of additional $\mathrm{ZnS}$ shell layers for $40 \mathrm{~min}$, the reaction flask was cooled and hexane $(5 \mathrm{~mL})$ was added. The cleaning procedure was similar to the thin-shell recipe. In both syntheses, no side products were observed during the cleaning processes pointing out high reaction yield.

\section{Supporting Information}

Supporting Information is available from the Wiley Online Library or from the author.

\section{Acknowledgements}

The authors gratefully acknowledge the financial support from the Singapore National Research Foundation under the programs of NRF-NRFI2016-08 and NRF-CRP-6-2010-02 and Agency for Science, Technology and Research ( $A * S T A R)$ of Singapore and in part from TUBITAK 114F326 and 115E679. H.V.D. acknowledges the support from ESF-EURYI and TUBA. E.M would like to thank the support from TUBA-GEBIP, and E.M. and Y.A. acknowledge funding from Abdullah Gul University Scientific Research Project no. FDK-201796. K.G. and O. E. acknowledge support from TUBITAK BIDEB 2211 program. Authors further acknowledge Mustafa Guler for his support in TEM characterizations. Y.K. acknowledges the funding from the European Union's Horizon 2020 Research and Innovation Programme under the Marie Skłodowska-Curie grant agreement 798697. Authors acknowledge support of the Scientific Center for Optical and Electron Microscopy (ScopeM) of the Swiss Federal Institute of Technology ETHZ.

\section{Conflict of Interest}

The authors declare no conflict of interest.

\section{Keywords}

core/shell nanocrystals, hot-injection growth, nanoplatelets, optical gain, semiconductor nanocrystals, stability

Received: November 18, 2018

Revised: December 31, 2018

Published online: January 30, 2019

[1] D. V. Talapin, J.-S. Lee, M. V. Kovalenko, E. V. Shevchenko, Chem. Rev. 2010, 110, 389.

[2] C. B. Murray, D. J. Norris, M. G. Bawendi, J. Am. Chem. Soc. 1993, $115,8706$.

[3] M. A. Hines, P. Guyot-Sionnest, J. Phys. Chem. 1996, 100, 468.

[4] B. O. Dabbousi, J. Rodriguez-Viejo, F. V. Mikulec, J. R. Heine, H. Mattoussi, R. Ober, K. F. Jensen, M. G. Bawendi, J. Phys. Chem. B 1997, 101, 9463.

[5] Z. A. Peng, X. Peng, J. Am. Chem. Soc. 2001, 123, 183.

[6] O. I. Micic, C. J. Curtis, K. M. Jones, J. R. Sprague, A. J. Nozik, J. Phys. Chem. 1994, 98, 4966.

[7] Y. Altintas, S. Genc, M. Y. Talpur, E. Mutlugun, Nanotechnology 2016, 27, 295604.

[8] S. Ithurria, B. Dubertret, J. Am. Chem. Soc. 2008, 130, 16504.

[9] M. Olutas, B. Guzelturk, Y. Kelestemur, A. Yeltik, S. Delikanli, H. V. Demir, ACS Nano 2015, 9, 5041.

[10] M. D. Tessier, C. Javaux, I. Maksimovic, V. Loriette, B. Dubertret, ACS Nano 2012, 6, 6751.

[11] A. Yeltik, S. Delikanli, M. Olutas, Y. Kelestemur, B. Guzelturk, H. V. Demir, J. Phys. Chem. C 2015, 119, 26768.

[12] C. She, I. Fedin, D. S. Dolzhnikov, A. Demortière, R. D. Schaller, M. Pelton, D. V. Talapin, Nano Lett. 2014, 14, 2772.

[13] B. Guzelturk, Y. Kelestemur, M. Olutas, S. Delikanli, H. V. Demir, ACS Nano 2014, 8, 6599.

[14] B. Liu, S. Delikanli, Y. Gao, D. Dede, K. Gungor, H. V. Demir, Nano Energy 2018, 47, 115.

[15] S. J. Lim, W. Kim, S. K. Shin, J. Am. Chem. Soc. 2012, 134, 7576.

[16] M. D. Tessier, B. Mahler, B. Nadal, H. Heuclin, S. Pedetti, B. Dubertret, Nano Lett. 2013, 13, 3321.

[17] S. Ithurria, D. V. Talapin, J. Am. Chem. Soc. 2012, 134, 18585.

[18] J. Zhou, M. Zhu, R. Meng, H. Qin, X. Peng, J. Am. Chem. Soc. 2017, 139, 16556.

[19] C. E. Rowland, I. Fedin, B. T. Diroll, Y. Liu, D. V. Talapin, R. D. Schaller, J. Phys. Chem. Lett. 2018, 9, 286.

[20] A. Polovitsyn, Z. Dang, J. L. Movilla, B. Martín-García, A. H. Khan, G. H. V. Bertrand, R. Brescia, I. Moreels, Chem. Mater. 2017, 29, 5671.

[21] B. Mahler, B. Nadal, C. Bouet, G. Patriarche, B. Dubertret, J. Am. Chem. Soc. 2012, 134, 18591.

[22] A. A. Rossinelli, A. Riedinger, P. Marqués-Gallego, P. N. Knüsel, F. V. Antolinez, D. J. Norris, Chem. Commun. 2017, 53, 9938.

[23] S. Yadav, A. Singh, L. Thulasidharan, S. Sapra, J. Phys. Chem. C 2018, 122, 820. 
[24] H. Cruguel, C. Livache, B. Martinez, S. Pedetti, D. Pierucci, E. Izquierdo, M. Dufour, S. Ithurria, H. Aubin, A. Ouerghi, E. Lacaze, M. G. Silly, B. Dubertret, E. Lhuillier, Appl. Phys. Lett. 2017, 110, 152103.

[25] J. Cui, A. P. Beyler, I. Coropceanu, L. Cleary, T. R. Avila, Y. Chen, J. M. Cordero, S. L. Heathcote, D. K. Harris, O. Chen, J. Cao, M. G. Bawendi, Nano Lett. 2016, 16, 289.

[26] L. T. Kunneman, J. M. Schins, S. Pedetti, H. Heuclin, F. C. Grozema, A. J. Houtepen, B. Dubertret, L. D. A. Siebbeles, Nano Lett. 2014, 14, 7039.

[27] M. L. H. Green, J. Organomet. Chem. 1995, 500, 127.

[28] M. L. H. Green, G. Parkin, J. Chem. Educ. 2014, 91, 807.

[29] B. Fritzinger, R. K. Capek, K. Lambert, J. C. Martins, Z. Hens, J. Am. Chem. Soc.132, 2010, 10195.

[30] F. Yan, J. Xing, G. Xing, L. Quan, S. T. Tan, J. Zhao, R. Su, L. Zhang, S. Chen, Y. Zhao, A. Huan, E. H. Sargent, Q. Xiong, H. V. Demir, Nano Lett. 2018, 18, 3157.

[31] P. Ramasamy, D. H. Lim, B. Kim, S. H. Lee, M. S. Lee, J. S. Lee, Chem. Commun. 2016, 52, 2067.

[32] Y. Bi, S. Pradhan, S. Gupta, M. Z. Akgul, A. Stavrinadis, G. Konstantatos, Adv. Mater. 2018, 30, 1.

[33] J. Q. Grim, S. Christodoulou, F. Di Stasio, R. Krahne, R. Cingolani, L. Manna, I. Moreels, Nat. Nanotechnol. 2014, 9, 891.

[34] C. E. Rowland, R. D. Schaller, J. Phys. Chem. C 2013, 117, 17337.

[35] H. C. Y. Yu, S. G. Leon-Saval, A. Argyros, G. W. Barton, Appl. Opt. 2010, 49, 2749
[36] Y. Zhao, C. Riemersma, F. Pietra, R. Koole, C. De Mello Donegá, A. Meijerink, ACS Nano 2012, 6, 9058.

[37] B. T. Diroll, C. B. Murray, ACS Nano 2014, 8, 6466.

[38] C. E. Rowland, W. Liu, D. C. Hannah, M. K. Y. Chan, D. V. Talapin, R. D. Schaller, ACS Nano 2014, 8, 977.

[39] N. Wang, S. Koh, B. G. Jeong, D. Lee, W. D. Kim, K. Park, M. K. Nam, K. Lee, Y. Kim, B. H. Lee, K. Lee, W. K. Bae, D. C. Lee, Nanotechnology 2017, 28, 185603.

[40] J. S. Steckel, J. Ho, C. Hamilton, J. Xi, C. Breen, W. Liu, P. Allen, S. Coe-Sullivan, J. Soc. Inf. Disp. 2015, 23, 294.

[41] O. Chen, J. Zhao, V. P. Chauhan, J. Cui, C. Wong, D. K. Harris, H. Wei, H. S. Han, D. Fukumura, R. K. Jain, M. G. Bawendi, Nat. Mater. 2013, 12, 445.

[42] M. Pelton, J. Phys. Chem. C 2018, 122, 10659

[43] B. Guzelturk, Y. Kelestemur, K. Gungor, A. Yeltik, M. Z. Akgul, Y. Wang, R. Chen, C. Dang, H. Sun, H. V. Demir, Adv. Mater. 2015, 27, 2741.

[44] V. I. Klimov, A. A. Mikhailovsky, D. W. McBranch, C. A. Leatherdale, M. G. Bawendi, Science 2000, 287, 1011.

[45] Q. Li, T. Lian, Nano Lett. 2017, 17, 3152.

[46] Y. Kelestemur, B. Guzelturk, O. Erdem, M. Olutas, K. Gungor, H. V. Demir, Adv. Funct. Mater. 2016, 26, 3570.

[47] Y. Kelestemur, D. Dede, K. Gungor, C. F. Usanmaz, O. Erdem, H. V. Demir, Chem. Mater. 2017, 29, 4857.

[48] H. C. Wang, H. Zhang, H. Y. Chen, H. C. Yeh, M. R. Tseng, R. J. Chung, S. Chen, R. S. Liu, Small 2017, 13, 1. 